\title{
First Febrile Urinary Tract Infection - Clinico-Biological Correlation with Imaging Studies - A Prospective Study
}

Vijayakumar M*, Geminiganesan S, Priyadarshini S, Sudha E and Prahlad N

Department of Pediatric Nephrology, Dr Mehta Children's Hospitals, Chennai, India

“Corresponding author: Vijayakumar M, Head of the Department of Pediatric Nephrology, Dr Mehta Children's Hospitals, 2(e), McNichols Road, 2nd Street, Chetpet, Chennai 600031,Email: doctormvk@gmail.com

Rec date: Feb 17, 2014, Acc date: Apr 28, 2014, Pub date: May 1, 2014

Copyright: (C) 2014 Vijayakumar M, et al. This is an open-access article distributed under the terms of the Creative Commons Attribution License, which permits unrestricted use, distribution, and reproduction in any medium, provided the original author and source are credited.

\begin{abstract}
Febrile urinary tract infection is one of the commonest infections in the childhood. Unrecognized and untreated childhood UTI can lead to scarring of the growing kidneys with subsequent hypertension and renal failure. This study has been done at a tertiary care medical centre to study the clinico - biological and imaging correlation in children with first episode of febrile UTI. Renal function tests, ultrasonogram, DMSA and MCU were done according to ISPN and institutional protocol. Imaging was done on follow up as per need. Majority of the children were found to be in 1 to 5 years age $(68 \%)$ group and overall there was female preponderance $(n=80 ; 53 \%)$. Dysuria was the commonest presentation in febrile UTI and E. coli, the commonest organism isolated. USG was found abnormal in $57.6 \%$ of children and DMSA done in acute phase picked up pyelonephritis in $81.5 \%$. MCU revealed VUR in $39 \%$ of the study population. The study underlines the importance and efficacy of various investigations apart from the clinical presentation in diagnosing UTI and defining the associated risk factors.
\end{abstract}

Keywords: Childhood UTI; First febrile UTI; DMSA scan Vesicoureteric reflux

\section{Introduction}

Febrile urinary tract infection (UTI) is one of the commonest infections in children next only to respiratory infections. Accurate diagnosis and early treatment of acute UTI and pyelonephritis is essential. A quick and readily available diagnostic test would be valuable for the early diagnosis of acute pyelonephritis. This helps to decrease the extent of renal scarring and subsequent secondary hypertension and renal failure by instituting proper and complete treatment. This study had been carried out in a tertiary pediatric referral unit in a developing country to determine the clinicobiological and imaging correlation of first febrile urinary tract infection.

\section{Methods and Materials}

Aims and objectives: 1 . To study the presenting clinical features at the time of documenting first episode of febrile UTI. 2. To study the essential biological and radiological findings in them and to correlate one to the other in predicting acute pyelonephritis and 3. To study the efficacy of DMSA in acute phase in children with acute pyelonephritis; this will help in proper and complete treatment to prevent complications.

Study design: A prospective and longitudinal study

Place of study: Mehta Children's Hospital, Chennai

Study period: June 2011 to December 2012

Inclusion criteria: 1 . Children of both sexes from after one month of age up to 12 years and 2. First episode of febrile culture positive UTI
Exclusion criteria: 1 . Children up to 1 month old 2. Recurrent UTI 3. Children with first episode of culture positive UTI who could not complete the evaluation as per our protocol and 4 . Children who did not complete the follow-up period of 1 year.

Statistical methods: Statsistical analysis was done using SSPS software. Demographic values have been given in frequencies with their percentages. Association between clinical, biological and imaging features were analyzed using Chi Square test; $\mathrm{P} \leq 0.05$ was taken as significant.

Study method: The presenting symptoms and clinical signs formed the clinical profile. As per our unit protocol irregular bowels were defined as passage of hard stools and/or constipation. Essential biological, ultrasonogram (USG) evaluation along with dimercaptosuccinic acid scintigraphy [DMSA] and micturating cystourethrogram [MCU] were performed as per Indian Society of Pediatric Nephrology (ISPN) guidelines which states that all infants with UTI be screened by USG, followed by MCU and DMSA scintigraphy. Since older patients (1-5 year old) with significant reflux and scars or urinary tract anomalies are likely to show abnormalities on ultrasonography or scintigraphy, a MCU in this age group is advised only in patients having abnormalities on either of the above investigations. Children older than 5 years are screened by ultrasonography and further evaluated only if this is abnormal. As per ISPN guidelines, children more than 5 years of age had regular USG but they also had DMSA in the first instance if clinically sick as per our protocol which is away from ISPN guidelines. As per ISPN guidelines, grade I, II, III VUR which are more likely to resolve are low grade reflux, whereas grade IV, $\mathrm{V}$ are considered as high grade reflux.

Investigations like urine routine, spot urine protein/creatinine ratio, urine culture and sensitivity, complete blood count, serum electrolytes [sodium, potassium, chloride, bicarbonate] and serum creatinine were done for all children. UTI was treated with parenteral or oral antibiotics as per ISPN guidelines followed by chemoprophylaxis as 
Citation: Vijayakumar M, Geminiganesan S, Priyadarshini S, Sudha E, Prahlad N (2014) First Febrile Urinary Tract Infection - Clinico-Biological Correlation with Imaging Studies - A Prospective Study. J Nephrol Therapeutic 4: 160. doi:10.4172/2161-0959.1000160

Page 2 of 4

per need. Bladder training was given in the form of timed and double voiding. Follow up USG was done for all the children enrolled in the study. For children who showed initial cystitis on USG, repeat USG was done after 3 months of treatment and for the rest of the study group, it was done at the end of 1 year. Repeat DMSA was done between 6 months to 1 year follow-up period in children who had abnormal imaging during initial evaluation. Our Institutional Ethical Committee approval was also obtained for our study.

\section{Observations and Results}

A total of 151 children with ages between more than 1 month upto 12 years with first episode of febrile culture positive UTI were evaluated in this study. The mean age of the study population was 2.35 \pm 2.33 yrs out of which $58(38.4 \%)$ children were less than 1 year old, $68(45 \%)$ children were in the age group of 1 to 5 years old and $25(16.6 \%)$ children were more than 5 years old (Table 1$)$. Eighty $(53 \%)$ children in the study group were females and $71(47 \%)$ were males (Figure 1). Twenty four (17\%) children were circumcised. Male gender predominated in less than 1year age group $(n-31 ; 53.4 \%)$ whereas female gender formed the majority in more than 1year old children (n-53\%; 66.3\%). In our study, common risk factors were anomalous urinary tract $(n-49 ; 32.5 \%)$, irregular bowels $(n-38 ; 25.2 \%)$ and phimosis $(n-8 ; 5.3 \%)$. Fever was present in $100 \%$ of the study group as febrile UTI was the inclusion criteria to begin with. Dysuria was the most common symptom which was seen in 61(40.3\%) children. Followed by frequency in $44(29.1 \%)$, vomiting in $13(8.6 \%)$ and other symptoms like abdominal pain, enuresis in the rest (22\%) (Table 2). E. coli was the commonest organism $(80.8 \%)$ isolated in all age groups (Figure 2). Klebsiella was the second most common organism found (9.3\%) followed by pseudomonas (3.3\%) and others (2.6\%). Majority of the children, $129(85.4 \%)$ were treated on out-patient basis whereas only $22(14.6 \%)$ needed in-patient care out of which 11 (50\%) were less than 1 year old. Among 151 children, 115(76.2\%) had pyuria, 14(9.3\%) had microscopic hematuria and 14(9.3\%) had 1+ and 26(17.2\%) had $2+$ proteinuria by dipstick method. Majority of the children $106(70.2 \%)$ had leucocytosis with the mean of $16,685.4 \pm 6622.4 / \mathrm{mm} 3$. Forty four $(29.1 \%)$ children had normal white blood cell count and only one $(0.7 \%)$ child presented with leucopenia. All children had normal serum creatinine and electrolytes at presentation. Children underwent imaging studies which included USG, DMSA and MCU (Table 3). Initial USG abdomen showed abnormality in $87(57.6 \%)$ children. Renomegaly was the commonest finding seen in $62(71.2 \%)$ children and 25(28.8\%) children showed changes of cystitis. DMSA in the acute phase picked up acute pyelonephritis in 123(81.5\%) children out of which $42(34.1 \%)$ were less than 1 year old, 59(48\%) were between 1 and 5 years of age and 22(17.9\%) were more than 5years old. All children with UTI were treated with intravenous or oral antibiotics for a period of 10 to 14 days depending upon the clinical presentation. MCU done after adequate control of acute infection followed by a minimum period of 4 weeks of chemoprophylaxis, picked up VUR in 59(39\%) children, with low grade reflux in $44(74.6 \%)$ and high grade reflux in 15(25.4\%). MCU showed VUR in 8 children in the age group of less than 1 year with normal USG and DMSA. Repeat USG done as per our protocol was found normal in 129(8.4\%). Twenty two (14.6\%) children had abnormal USG including one sided small kidney (9.9\%) and other structural anomalies already documented in the first instance.

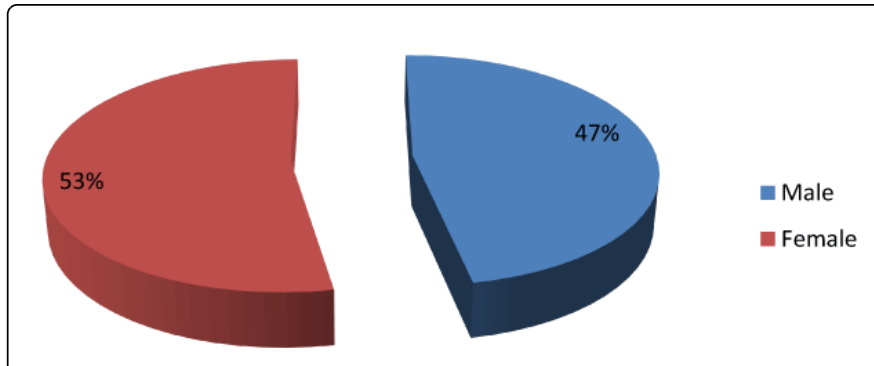

Figure 1: Sex distribution (n 151)

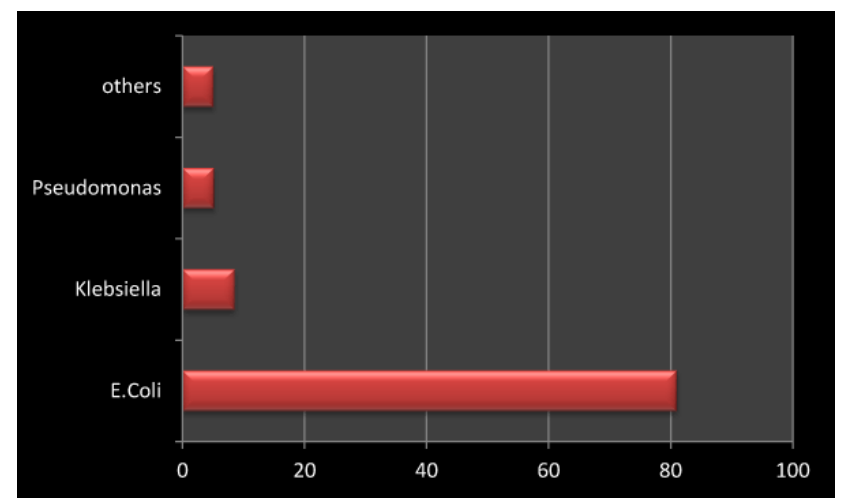

Figure 2: Bacterial isolates in urine

\begin{tabular}{|l|l|l|l|}
\hline Sex & Less than $\mathbf{1}$ year & $\mathbf{1}$ to $\mathbf{5}$ year & More than $\mathbf{5}$ years \\
\hline Males & $31(53.4 \%)$ & $33(48.5 \%)$ & $7(28 \%)$ \\
\hline Females & $27(46.6 \%)$ & $35(51.5 \%)$ & $18(72 \%)$ \\
\hline Total & $58(38.4 \%)$ & $68(45 \%)$ & $25(16.6 \%)$ \\
\hline
\end{tabular}

Table 1: Age and sex distribution of UTI (n-151)

\begin{tabular}{|lll|}
\hline Clinical Features & Number & Percentage (\%) \\
Fever & 151 & 100 \\
Frequency & 44 & 29.1 \\
Dysuria & 61 & 40.4 \\
Vomiting & 13 & 8.6 \\
Others & 33 & 21.9 \\
\hline
\end{tabular}

Table 2: Clinical features of UTI in children (n-151)

\begin{tabular}{|l|l|l|l|l|}
\hline Age & Initial USG & Initial DMSA & Initial MCU & Repeat DMSA \\
\hline $\begin{array}{l}\text { Less than } \\
\text { year }\end{array}$ & $\mathbf{2 9 ( 3 3 . 3 \% )}$ & $42(34.1 \%)$ & $26(44.1 \%)$ & $10(22.7 \%)$ \\
\hline $\mathbf{1}$ to 5years & $40(46 \%)$ & $59(48 \%)$ & $25(42.4 \%)$ & $24(54.6 \%)$ \\
\hline
\end{tabular}


Citation: Vijayakumar M, Geminiganesan S, Priyadarshini S, Sudha E, Prahlad N (2014) First Febrile Urinary Tract Infection - Clinico-Biological Correlation with Imaging Studies - A Prospective Study. J Nephrol Therapeutic 4: 160. doi:10.4172/2161-0959.1000160

Page 3 of 4

\begin{tabular}{|l|l|l|l|l|}
\hline $\begin{array}{l}\text { More than } \mathbf{5} \\
\text { years }\end{array}$ & $18(20.7 \%)$ & $22(17.9 \%)$ & $8(13.6 \%)$ & $10(22.7 \%)$ \\
\hline
\end{tabular}

Table 3: Abnormal imaging in children with UTI in various age groups

\section{Discussion}

Urinary tract infection (UTI) is defined as growth of significant number of organism of single species in urine associated with symptoms [1]. It is one of the commonest bacterial infection in children especially in those less than 5 years old. As per ISPN guidelines UTI is more common in males during infancy and there is female preponderance thereafter [1-3]. Taneja et al. in their study of 143 infants with culture positive UTI, found male preponderance, with 116 being males and 27 females [3]. In our study also we found male predominance in children less than 1 year old (53.4\%). In contrast to the study done by Sharma et al. who found fever as the commonest presenting symptom followed by abdominal pain, we found dysuria as the commonest symptom in children with febrile UTI [4]. As per the ISPN guidelines, common risk factors usually associated with UTI include children aged less than 1 year, male gender, vesicoureteric reflux and posterior urtheral valves. In the recent guideline by ISPN, bowel bladder dysfunction was also considered as an important risk factor, emphasizing the importance of its prompt recognition and management [1]. In our study, common risk factors were anomalous urinary tract $(32.5 \%)$, irregular bowels $(25.2 \%)$ and phimosis $(5.3 \%)$. Escherichia coli is the most common pathogen identified in $80 \%$ to $90 \%$ of children with first attack of UTI $[5,6]$. Taneja et al. and Sharma et al. in their studies found E. coli to be the commonest organism implicated in UTI with Klebsiella being the second most common $[3,4]$. The above studies are in concordance with our finding where in E. coli was the commonest organism isolated (80.8\%) with klebsiella being the second most common (9.3\%).

USG is useful for detecting anatomic abnormalities of kidneys and urinary tract apart from detecting suspicious features of acute pyelonephritis like renomegaly, pyelitis and turbid urinary contents [7]. Montini et al. analyzed data of 300 children with acute pyelonephiritis with USG evaluation and found that USG detected VUR only in $27.27 \%$. The ability of USG to predict the renal parenchymal damage was also limited to only $26.66 \%$ and they were found to have parenchymal scarring by DMSA [8]. In our study, USG showed signs of pyelonephritis in 62(71.2\%) children and cystitis in 25(28.8\%). Kidney scarring related to UTI has been considered a cause of substantial long-term morbidity [9]. DMSA is the gold standard for diagnosing acute pyelonephritis and renal scars. In the acute phase of illness, it will help in confirming acute pyelonephritis $[10,11]$. Approximately $60 \%$ of children with febrile UTI, when evaluated in the acute phase with DMSA, will have features of pyelonephritis. Ten to $40 \%$ of these will have permanent renal scarring [12,13]. To know the usefulness of DMSA in diagnosing acute pyelonephritis, it was done in acute phase in our protocol. Jakobsson et al. studied 185 children with UTI and he also did DMSA in the acute phase. In his study he found that $85 \%$ of the study population had abnormal DMSA in the acute phase, $47 \%$ had persistent abnormality in repeat DMSA which was done after 5 months. Montini et al. had also shown that the acute phase DMSA scan exhibited features of acute pyelonephritis in $54 \%$ of children. The follow-up DMSA scan showed scarring in $28 \%$ of those with initial diagnosis of acute pyelonephritis. He concluded that DMSA should be done 6 months after infection to detect scarring that may be lead to hypertension and proteinuria [8]. In our center, DMSA in acute phase picked up acute pyelonephritis in $81.5 \%$ children, follow-up scan done between 6 months to 1 year revealed evidence of scars in $44(29.1 \%)$ children. It is important to distinguish between acute pyelonephritis and lower UTI, because renal parenchymal involvement can lead to permanent renal damage and chronic kidney disease in a growing kidney [14].

Clinicobiological features to predict renal imaging including that of DMSA had been attempted in various studies. Procalcitonin as an acute phase reactant was more superior compared to CRP or white blood cell count for identifying APN during early stages of UTI [15]. Further from the Study of the Working Group of the Clinical Practice Guidelines for UTI in children, we can identify the recommendations of the possibility of acute pyelonephritis from various clinicobiological features like $>38^{\circ} \mathrm{C}$ fever, systemic involvement, serum procalcitonin and C- reactive protein as well as interleukin- 6 in urine. But direct correlations of clinicobiological features with various stages of imaging abnormalities are clearly lacking [16].

Primary vesicoureteral reflux (VUR) is the commonest congenital urinary tract abnormalities in childhood, which is usually diagnosed after an episode of UTI [17]. Hence the evaluation of UTI is complete only with MCU. It is a known fact that VUR is not a prerequisite for renal involvement among febrile UTI children $[18,19]$. Pecile et al. in their study showed VUR in 74(24\%) children out of 208 studied. He also concluded that there was no significant difference in the incidence of VUR among children with or without renal lesions [20]. In our study MCU picked up VUR in 39\% children of whom $74.6 \%$ had low grades of reflux and only $25.4 \%$ had high grade reflux. There was no statistical significance between the children with APN and VUR. Abnormal imaging in children with UTI in various age groups is shown in Table 3 and various imaging correlation as predictors of renal damage is shown in Table 4. Out of 151 children, 64 had normal USG, but had DMSA abnormality. Hence predicting the renal parenchymal damage by USG is limited. Though the DMSA yielded positive results in 132 children, only 44 had VUR. This showed VUR may not be mandatory to produce parenchymal changes in DMSA. As this study was conducted in a tertiary care hospital with a selected cohort of children, selection bias is unavoidable. We recommend that this study should be conducted on a large scale in a general pediatric population to avoid the selection bias.

\begin{tabular}{|c|c|c|c|c|c|c|c|c|}
\hline & \multicolumn{2}{|l|}{$\mathrm{n}$} & \multicolumn{2}{|c|}{$\begin{array}{l}\text { Estimate } \\
\text { (\%) }\end{array}$} & \multicolumn{4}{|c|}{ Likelihood Ratio } \\
\hline & $\begin{array}{l}\text { Abnor } \\
\text { mal } \\
\text { DMSA }\end{array}$ & $\begin{array}{l}\text { Norma } \\
\text { I } \\
\text { DMSA }\end{array}$ & $\begin{array}{l}\mathrm{PP} \\
\mathrm{V}\end{array}$ & NPV & $\begin{array}{l}\text { Sensit } \\
\text { ivity }\end{array}$ & $\begin{array}{l}\text { Specifi } \\
\text { city }\end{array}$ & $\begin{array}{l}\text { Positi } \\
\text { ve }\end{array}$ & $\begin{array}{l}\text { Negativ } \\
\text { e }\end{array}$ \\
\hline \multicolumn{9}{|l|}{ USG } \\
\hline $\begin{array}{l}\text { Abnor } \\
\text { mal }\end{array}$ & 62 & 9 & $\begin{array}{l}87 . \\
3\end{array}$ & 20 & 49.2 & 64 & 1.36 & 0.79 \\
\hline $\begin{array}{l}\text { Norma } \\
\text { I }\end{array}$ & 64 & 16 & & & & & & \\
\hline \multicolumn{9}{|l|}{ MCU } \\
\hline VUR & 44 & 11 & 80 & 2.2 & 33.3 & 15.3 & 0.39 & 4.35 \\
\hline $\begin{array}{l}\text { No } \\
\text { VUR }\end{array}$ & 88 & 2 & & & & & & \\
\hline
\end{tabular}

Table 4: USG and MCU findings as Predictors of Parenchymal Renal Damage on DMSA Scans 
Citation: Vijayakumar M, Geminiganesan S, Priyadarshini S, Sudha E, Prahlad N (2014) First Febrile Urinary Tract Infection - Clinico-Biological Correlation with Imaging Studies - A Prospective Study. J Nephrol Therapeutic 4: 160. doi:10.4172/2161-0959.1000160

Page 4 of 4

\section{Conclusion}

UTI is one of the commonest infections in children, with a potential risk for complications such as renal scarring. The diagnosis and prompt as well as aggressive treatment of UTI is very important in young children as it may be a marker of urinary tract anomaly also. Early diagnosis and adequate treatment helps the children to have normal renal function of the growing kidneys. DMSA in acute phase definitely plays a major role in confirming acute pyelonephritis and thereby decision on complete treatment. If childhood UTI up to 5 years of age is not evaluated and treated properly then it becomes an important risk factor for the development of proteinuria, hypertension and end stage renal disease. Early intervention in childhood may prevent future complications.

\section{Acknowledgement}

We are thankful to Mr. R.Srinivasan, Technical Officer, National Institute for Research in Tuberculosis, ICMR, and Chennai for helping us with the statistical analysis of our work.

\section{Contributors:}

MVK, SG and SP prepared the manuscript after literature search and analysis of the data. All of them were involved in the management of patients.

\section{Funding:}

None

Competing interests:

None

\section{References}

1. Indian Society of Pediatric Nephrology, Vijayakumar M, Kanitkar M, Nammalwar BR, Bagga A (2011) Revised statement on management of urinary tract infections. Indian Pediatr 48: 709-717.

2. Ismail $\mathrm{K}$, Wissing $\mathrm{KM}$, Lolin $\mathrm{K}$, Le PQ, Christophe $\mathrm{C}$, et al. (2011) Characteristics of First Urinary Tract Infection With Fever in Children. A Prospective Clinical and Imaging Study. The Pediatric Infectious Disease Journal 30: 371-374.

3. Taneja N, Chatterjee SS, Singh M, Singh S, Sharma M (2010) Pediatric urinary tract infections in a tertiary care center from north India. Indian J Med Res 131: 101-105.

4. Sharma A, Shrestha S, Upadhyay S, Rijal P (2011) Clinical and bacteriological profile of urinary tract infection in children at Nepal Medical College Teaching Hospital. Nepal Med Coll J 13: 24-26.
5. Chishti AS1, Maul EC, Nazario RJ, Bennett JS, Kiessling SG (2010) A guideline for the inpatient care of children with pyelonephritis. Ann Saudi Med 30: 341-349.

6. Raszka WV Jr, Khan O (2005) Pyelonephritis. Pediatr Rev 26: 364-370.

7. Sudha E, Vijayakumar M (2013) Urinary Tract Infection in Children. In: Vijayakumar M, Nammalwar BR(Eds). Principles and Practice of Pediatric Nephrology, 2nd edition. New Delhi: Jaypee Brothers Medical Publishers (P) Ltd; 2013. Pp 748-766.

8. Montini G, Zucchetta P, Tomasi L, Talenti E, Rigamonti W, et al. (2009) Value of imaging studies after a first febrile urinary tract infection in young children: data from Italian renal infection study 1 . Pediatrics 123: e239-246.

9. Montini G, Tullus K, Hewitt I (2011) Febrile urinary tract infections in children. N Engl J Med 365: 239-250.

10. Saadeh SA, Mattoo TK (2011) Managing urinary tract infections. Pediatr Nephrol 26: 1967-1976.

11. Craig JC, Wheeler DM, Irwig L, Howman-Giles RB (2000) How accurate is dimercaptosuccinic acid scintigraphy for the diagnosis of acute pyelonephritis? A meta-analysis of experimental studies. J Nucl Med 41: 986-993.

12. Jakobsson B, Svensson L (1997) Transient pyelonephritic changes on 99mTechnetium-dimercaptosuccinic acid scan for at least five months after infection. Acta Paediatr 86: 803-807.

13. Hoberman A, Wald ER, Hickey RW, Baskin M, Charron M, et al. (1999) Oral versus initial intravenous therapy for urinary tract infections in young febrile children. Pediatrics 104: 79-86.

14. Dimitrios Doganis, Konstantinos Siafas, Myrsini Mavrikou, George Issaris, Anna Martirosova, et al. (2007) Does early treatment of urinary tract infection prevent renal damage? Pediatrics 120:e922-e928.

15. Leroy S, Fernandez-Lopez A, Nikfar R, Romanello C, Bouissou F, et al. (2013) Association of procalcitonin with acute pyelonephritis and renal scars in pediatric UTI. Pediatrics 131: 870-879.

16. Working Group of the Clinical Practice Guidelines for Urinary Tract Infection in Children. Clinical practice guideline for urinary tract infection in children. Madrid (Spain): Ministry of Health National Health Service Quality Plan, Social and Equality Policy, Aragon Health Sciences Institute (I+CS); 2011.259 p. (SNS Clinical Practice Guidelines: I+CS; no. 2009/01).

17. Mattoo TK (2011) Vesicoureteral reflux and reflux nephropathy. Adv Chronic Kidney Dis 18: 348-354.

18. Gleeson FV, Gordon I (1991) Imaging in urinary tract infection. Arch Dis Child 66: 1282-1283.

19. Biggi A, Dardanelli L, Cussino P, Pomero G, Noello C, et al. (2001) Prognostic value of the acute DMSA scan in children with first urinary tract infection. Pediatr Nephrol 16: 800-804.

20. Pecile P, Miorin E, Romanello C, Vidal E, Contardo M, et al. (2009) Agerelated renal parenchymal lesions in children with first febrile urinary tract infections. Pediatrics 124: 23-29.
This article was originally published in a special issue, entitled: "Pediatric Nephrology", Edited by Dr. Moazzam Hossain, Bangabandhu Sheikh Mujib Medical University, Bangladesh 